\title{
Electron Density Distribution in the Topside Ionosphere of Mars and Associated Atmospheric Parameters
}

\author{
By \\ Siegfried J. Bauer \\ (Vorgelegt in der Sitzung der math.-nat. Klasse am 23. März 2006 \\ durch das w. M. Siegfried J. Bauer)
}

Radio occultation observations and more recently radar sounding are now providing a large number of electron density profiles of the Martian ionosphere [1-3]. With the demise of the Japanese Nozomi mission, aeronomical parameters for interpreting the Martian ionosphere are thus limited to the early observation on the American Viking mission [4].

That the principal ionospheric layer on Mars corresponds to a photo-chemical Chapman-type $F_{1}$ layer is now well established since its peak properties exhibit the expected solar control [5-7]. However the ionosphere of Mars (as that of Venus) deviates from a simple Chapman-layer, since its principal ion $\left(\mathrm{O}_{2}^{+}\right)$does not correspond to the ionizable constituent $\left(\mathrm{CO}_{2}\right)$, but results from an ion-atom interchange reaction with atomic oxygen originating in dissociative processes.

It was shown by the Viking RPA experiment [4] that above the ionospheric peak the lighter ion $\mathrm{O}^{+}$is also present in addition to $\mathrm{O}_{2}^{+}$. The distribution of $\mathrm{O}^{+}$showing a peak near $200 \mathrm{~km}$, seems to be the result of photochemistry below and plasma diffusion above it. Below the $\mathrm{O}^{+}$peak, this ion results from the equilibrium of photoionization of $\mathrm{O}$ and chemical loss via an ion-molecule reaction involving $\mathrm{CO}_{2}$, i.e., $\mathrm{O}^{+} \propto n(\mathrm{O}) / n\left(\mathrm{CO}_{2}\right)$ exhibiting an increase with altitude according to $\exp (z / H(28))$, i.e., corresponding to an effective mass $m\left(\mathrm{CO}_{2}\right)-m(\mathrm{O})$ in the scale height. Above the peak, $\mathrm{O}^{+}$is 
governed by plasma diffusion, although affected by the presence of the major ion $\mathrm{O}_{2}^{+}$. Thus, the $\mathrm{O}^{+}$distribution on Mars represents a "hidden" $F_{2}$ layer [8].

In the topside ionosphere the electron density distribution results from the ion species $\mathrm{O}_{2}^{+}$and $\mathrm{O}^{+}$in diffusive equilibrium. In contrast to neutral species, ion species in diffusive equilibrium are not independent of each other because of a polarization electric field set up to prevent charge separation. This field can counteract gravity for a lighter minor ion $\left(m_{2}\right)$ since it depends on the mean ion mass determined by the heavier major ion $\left(m_{1}\right)$ and the sum of the temperature of the electrons $T_{e}$ and ions $T_{i}$ that generally exceed the neutral gas temperature [8].

For a binary ion mixture with masses $m_{1}$ and $m_{2}$ controlled by plasma diffusion, the electron density distribution was first derived by the author four decades ago [9] as

$$
N(z)=N_{0} \exp \left[-\frac{1}{1+\epsilon}\left(\frac{z}{H_{1}}\right)-\ln \left(1+\eta \exp \left(\frac{z}{H_{12}}\right)\right)+\ln (1+\eta)\right],
$$

where $\epsilon=T_{e} / T_{i}, H_{1}=k T_{i} / m_{1} g, H_{12}=k T_{i} /\left(m_{1}-m_{2}\right) g$ and $\eta=$ $N\left(\mathrm{X}_{2}^{+}\right) / N\left(\mathrm{X}_{1}^{+}\right)$is the ion abundance ratio at the reference level $z=0$.

In the case of Mars $\mathrm{X}_{1}^{+} \equiv \mathrm{O}_{2}^{+}$and $\mathrm{X}_{2}^{+} \equiv \mathrm{O}^{+}$representing the appropriate binary ion mixture. For illustrative purposes Fig. 1 shows the topside electron density distribution according to Eq. (1) for different

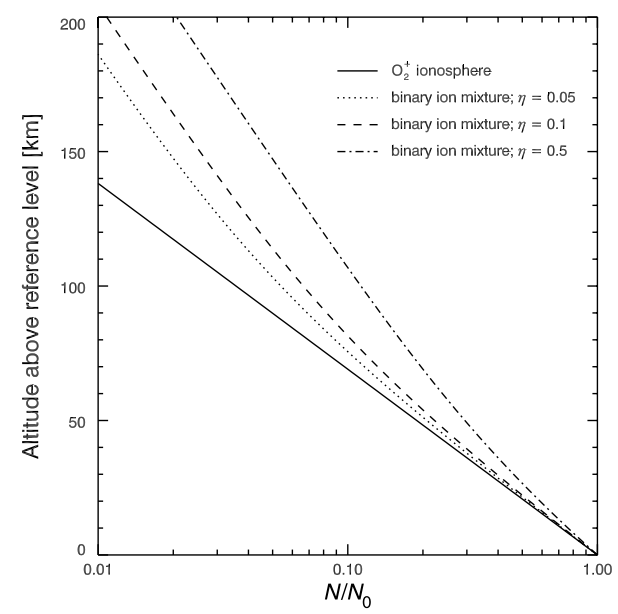

Fig. 1. Topside electron density distribution of a binary ion mixture $\left(\mathrm{O}_{2}^{+}+\mathrm{O}^{+}\right)$for various ion abundance ratios $\eta$ at $z=0$ 
ion abundance ratios $\eta$ at the reference level $z=0$, with $H_{1}=15 \mathrm{~km}$ and $H_{12}=30 \mathrm{~km}$, assuming thermal equilibrium $(\epsilon=1)$.

It is obvious that fitting observed electron density profiles with the distribution according to Eq. (1) should allow aeronomic parameters to be inferred from topside profiles above an altitude where plasma diffusion is expected to prevail. A reference level $z=0$ at altitudes $h \geq 180 \mathrm{~km}$ appears to be an appropriate choice. Thus, $T_{i}$ from scale height, absence of thermal equilibrium $(\epsilon>1)$ and the abundance ratio of neutral constituents $\mathrm{O}$ and $\mathrm{CO}_{2}$ from $\eta$ may be obtained by fitting observed topside profiles, providing useful constraints for models of the upper atmosphere of Mars [10].

\section{Acknowledgement}

The help of M. Rieger in the preparation of Fig. 1 is gratefully acknowledged.

\section{References}

[1] Hinson, D. P., Simpson, R. A., Twicken, J. D., Tyler, G. L., Flasar, F. M. (1999) Initial results from the radio occultation measurements with Mars Global Surveyor. J. Geophys. Res. 104: 26997-27012

[2] PÄtzold, M., Tellmann, S., HÄusler, B., Hinson, D., SchaA, R., Tyler, G. L. (2005) A sporadic third layer in the ionosphere of Mars. Science 310: 837-839

[3] Gurnett, D. A., Kirchner, D. L., Huff, R. L., Morgan, D. D., Persoon, A. M., Averkamp, T. F., Duru, F., Nielsen, E., Safaeinili, A., Plalut, J. J., PiCARdi, G. (2005) Radar soundings of the ionosphere of Mars. Science 310: 1929-1933

[4] Hanson, W. B., SANATANi, S., ZucCARo, D. R. (1977) The Martian ionosphere as observed by the Viking retarding potential analyzers. J. Geophys. Res. 82: $4357-4363$

[5] Hantsch, M., BAUER, S. J. (1987) Solar control of the Mars ionosphere. Planet. Space Sci. 38: 3539-3542

[6] Breus, T. K., Krymskit, A. M., Crider, D. H., Ness, N. F., Hinson, D., BARASHYAN, K. K. (2004) Effect of solar radiation in the topside atmosphere/ ionosphere of Mars: Mars Global Surveyor observation. J. Geophys. Res. 109: A09310

[7] Rishbeth, H., Mendillo, M. (2004) Ionospheric layers of Mars and Earth. Planet. Space Sci. 52: $849-852$

[8] Bauer, S. J., LAmmer, H. (2004) Planetary Aeronomy. Springer, Berlin Heidelberg New York

[9] BAUER, S. J. (1962) The electron density distribution above the $F_{2}$ peak and associated atmospheric parameters. J. Atmos. Sci. 19: 235-240

[10] Bougher, S. W., Engel, S., Hinson, D. P., MurPhy, J. R. (2004) MGS radio science electron density profiles: Interannual variability and implications for the Martian neutral atmosphere. J. Geophys. Res. 109: E03010

Author's address: Dr. S. J. Bauer, Institut für Physik/IGAM, Karl-FranzensUniversität Graz, 8010 Graz, Austria. E-Mail: siegfried.bauer@uni-graz.at. 